\title{
Evaluasi Pengelolaan Program Penyediaan Air Minum dan Sanitasi Berbasis Masyarakat di Jorong Gurun Kecamatan Harau Kabupaten Lima Puluh Kota
}

\author{
Kiki Rizky Amalia \\ Dosen Fakultas Teknik Universitas Batanghari \\ Program Studi Teknik Sipil \\ Email : iqy.amalia@gmail.com
}

\begin{abstract}
Abstrak
Program penyediaan air minum dan sanitasi berbasis masyarakat merupakan salah satu program pembangunan infrastruktur pemerintah dalam memenuhi kebutuhan akses air minum dan sanitasi masyarakat. Fokus penelitian ini adalah untuk mengevaluasi pengelolaan program Pamsimas yang mengacu pada 5 aspek keberlanjutan program, yaitu keberlanjutan teknis, keberlanjutan pendanaan, keberlanjutan kelembagaan, keberlanjutan sosial dan keberlanjutan lingkungan di Jorong Gurun Kabupaten Lima Puluh Kota. Metode Penelitian dilakukan dengan survey lapangan dan wawancara. Dari hasil penelitian didapatkan bahwa setiap aspek saling berkaitan dan pengelolaan telah berhasil dilakukan dengan baik, Disini pengelolaan telah dilakukan. Perbaikan perlu dilakukan pada aspek keberlanjutan pendanaan dan keberlanjutan lingkungan, sehingga pengembangan sarana dan prasana dapat dilakukan secara mandiri.
\end{abstract}

Kata Kunci: Pengelolaan, Program Pamsimas, Keberlanjutan

\section{PENDAHULUAN}

Memiliki akses air minum yang layak adalah harapan seluruh lapisan masyarakat Indonesia, baik masyarakat yang tinggal di perkotaan maupun masyarakat yang tinggal di daerah pinggiran dan pedesaan, baik masyarakat yang berpenghasilan tinggi maupun masyarakat yang berpenghasilan rendah. Untuk dapat memiliki akses air minum yang layak ini, bisa diupayakan sendiri oleh masyarakat secara mandiri, berkelompok atau melalui bantuan pemerintah dalam proyek dan program pembangunan.

Program Penyediaan Air Minum dan Sanitasi Berbasis Mayarakat (Pamsimas) merupakan program pembangunan infrastruktur pemerintah dalam meningkatkan akses masyarakat pedesaan dan peri-urban terhadap fasilitas air minum dan sanitasi yang layak dengan pendekatan berbasis masyarakat.

Program Pamsimas diperuntukkan kepada lokasi yang membutuhkan dan bersedia memelihara serta mengelola sistem yang dibangun. Jorong Gurun Kecamatan Harau Kabupaten Limapuluh Kota merupakan salah satu daerah yang telah melaksanakan kegiatan program Pamsimas. Sejak tahun 2009 program Pamsimas di Jorong Gurun telah mengalami perkembangan, namun juga terdapat kendala dalam pemenuhan kebutuhan air minum di saat musim kemarau. Oleh sebab itu, perlu dilakukan evaluasi pengelolaan program Pamsimas untuk keberlanjutan program di masa yang akan datang.

\section{Air Bersih dan Kontinuitas}

Air merupakan unsur yang sangat penting dalam kehidupan makhluk hidup, yang berfungsi untuk kebutuhan manusia yaitu untuk minum. Air bersih adalah air yang dapat digunakan untuk kehidupan sehari-hari yang kualitasnya memenuhi syarat kesehatan dan akan menjadi air minum setelah melalui proses pengolahan (Permenkes RI No. 492 tahun 2010).

Kontinuitas dapat didefinisikan bahwa air bersih tersedia selama 24 jam per hari, dan selalu tersedia selama dibutuhkan. Akan tetapi kondisi tersebut belum dapat dipenuhi pada setiap wilayah di Indonesia, sehingga untuk menentukan tingkat kontinuitas pemakaian air 
dapat dilakukan dengan cara pendekatan aktifitas konsumen terhadap prioritas pemakaian air. Prioritas pemakaian air yaitu minimal selama 12 jam per hari (Kholiq, Abdul 2014).

\section{Sistem Penyediaan Air Bersih}

Menurut Cristiandi Richardo Mampuk (2014), Sistem penyediaan air bersih meliputi :

1. Unit air baku, merupakan bangunan untuk mengambil air baku dari sumber air dan dialirkan ke unit produksi melalui pipa transmisi. Misalnya, intake, broncaptering, bendung dan pompa.

2. Unit Produksi, merupakan usaha-usaha yang dilakukan untuk mengubah sifat-sifat suatu zat.

3. Unit Distribusi, dalam sistem distribusi air bersih yaitu dari reservoir distribusi dan jaringan pipa distribusi.

\section{Program Pamsimas}

Menurut Petunjuk teknis Pamsimas (2015), Penyediaan Air Minum dan Sanitasi Berbasis Masyarakat (PAMSIMAS) adalah salah satu program yang dilaksanakan oleh Pemerintah Indonesia dengan dukungan Bank Dunia, program ini dilaksanakan di wilayah perdesaan dan pinggiran kota, yang bertujuan untuk meningkatkan jumlah fasilitas pada warga masyarakat kurang terlayani termasuk masyarakat berpendapatan rendah di wilayah perdesaan dan peri-urban. Berdasarkan Petunjuk teknis Pamsimas (2015), Sesuai dengan amanat RPJPN 2005-2025 dan RPJM 2015-2019, Pemerintah melalui program pembangunan nasional 'Akses Universal Air Minum dan Sanitasi Tahun 2019', menetapkan bahwa pada tahun 2019, Indonesia dapat menyediakan layanan air minum dan sanitasi yang layak bagi $100 \%$ rakyat Indonesia. Untuk kebutuhan air minum, secara nasional sampai dengan tahun 2015 Indonesia baru mampu menyediakan akses yang layak bagi 68\% dari total penduduk Indonesia, sedangkan untuk kebutuhan sanitasi dasar, Indonesia baru mampu menyediakan akses sanitasi layak bagi $60 \%$ dari total penduduk Indonesia. Ruang lingkup program Pamsimas mencakup 5 (lima) komponen program yaitu:

1. Pemberdayaan masyarakat dan pengembangan kelembagaan daerah,

2. Peningkatan perilaku higienis dan pelayanan sanitasi,

3. Penyediaan sarana air minum dan sanitasi umum,

4. Insentif desa/kelurahan dan kabupaten/kota, dan

5. Dukungan manajemen pelaksanaan program

Adapun Konsep keberlanjutan yang dipakai dalam Program Pamsimas dalam pembangunan sarana SPAMS (juknis Pamsimas,2015) adalah:

1. Keberlanjutan teknis, mencakup kepada berfungsinya secara benar dan dapat diandalkan terhadap teknologi serta pelayanan sistem air minum dan dapat memberikan pelayanan dengan jumlah air yang memadai secara kontinu dengan kualitas air yang memenuhi standar kesehatan.

2. Keberlanjutan pendanaan, sistem hanya dapat berfungsi bila sumber pendanaan/finansial paling tidak dapat memenuhi kebutuhan untuk operasional, pemeliharaan dan perbaikan.

3. Keberlanjutan kelembagaan, apakah dalam proses pembentukan badan pengelola telah memperhatikan kesetaraan gender dan pelibatan kelompok miskin, serta mewujudkan nilainilai demokrasi dan transparansi, kelembagaan yang ada harus mempunyai karakteristik lokal, aturan dan akuntabilitas.

4. Keberlanjutan sosial, pemanfaat akan mendukung keberlanjutan sistem bila harapan mereka dapat terpenuhi, ini berarti bahwa pelayanan yang ada harus mudah mereka akses, yang mana pemanfaat diberikan pilihan untuk teknologi pelayanan sesuai dengan kemampuan pembiayaan, budaya dan tata cara keseharian. 
5. Keberlanjutan lingkungan, sumber air akan menghadapi banyak ancaman, seperti terlalu besarnya penyadapan, kontaminasi, penggundulan hutan, dan fasilitas/sarana air minum dan sanitasi sendiri juga akan menjadikan ancaman terhadap lingkungan.

\section{METODE PENELITIAN}

Objek penelitian difokuskan pada tahap pengelolaan yaitu pengoperasian, pemeliharaan, pemantauan dan pengembangan Program Pamsimas di Jorong Gurun Kecamatan Gurun Kabupaten Limapuluh Kota, Provinsi Sumatera Barat.

Teknik pengumpulan data pada penelitian ini adalah:

1. Survei Lapangan

Survei lapangan dilakukan dengan cara melakukan pengamatan langsung pada wilayah penelitian. Survei yang dilakukan dalam pengumpulan data penelitian ini adalah observasi nonpartisipan, karena dalam penelitian ini penulis hanya sebagai pengamat untuk kepentingan data penelitian dan tidak terlibat dengan aktifitas-aktifitas yang sedang dijalani di lokasi penelitian.

2. Wawancara

Jenis wawancara dalam penelitian ini adalah wawancara terstruktur yaitu wawancara yang dilakukan secara terencana yang berpedoman pada daftar pertanyaan yang telah disiapkan peneliti. Daftar pertanyaan terdiri dari 31 pertanyaan. Adapun responden pada penelitian ini dapat dilihat pada table 1 .

Tabel 1. Daftar Responden Penelitian

\begin{tabular}{lllc}
\hline No & \multicolumn{1}{c}{ Kategori } & \multicolumn{1}{c}{ Responden } & kode \\
\hline 1 & Pemerintah Daerah & Satker & DS \\
& & Pakem & PK \\
3 & Konsultan Kabupaten & District Koordinator & DC \\
& Tenaga Fasilitator Masyarakat & Fasilitator Senior & FS \\
& & (Keberlanjutan) Fasilitator Teknik & FT \\
& & Fasilitator Pemberdayaan & FB \\
4 & Pemerintah Nagari & Wali Jorong & PN \\
5 & Pelaksana Kegiatan & Kader AMPL & KA \\
& & Koordinator KKM Ketua Satlak & \\
& & Anggota BPSPAMS Tim & M1 \\
6 & Masyarakat & Penggadaan & M2 \\
& & Masyarakat 1 & M3 \\
& & Masyarakat 2 & M4 \\
& & Masyarakat 3 & M5 \\
\hline
\end{tabular}

Sumber : Data Olahan, 2017

\section{Dokumentasi}

Dokumentasi yang diperoleh dalam penelitian ini berupa foto-foto sarana dan prasarana penyediaan air minum dan sanitasi, foto-foto kegiatan program Pamsimas, Petunjuk Teknis Program Pamsimas, Artikel tentang Program Pamsimas.

\section{HASIL DAN PEMBAHASAN}

Di Jorong Gurun, Program Penyediaan air minum dan sanitasi berbasis masyarakat (Pamsimas) dimulai pada tahun 2009. Sarana dan prasarana yang telah dibangun dapat dilihat pada tabel 2. 
Tabel 2. Kondisi Sarana

\begin{tabular}{|c|c|c|c|}
\hline No & Sarana & Status & Jumlah \\
\hline 1 & Intake & $\begin{array}{l}\text { Berfungsi, Intake ke } 2 \text { digunakan pada saat musim } \\
\text { kemarau saja }\end{array}$ & 3 \\
\hline 2 & Reservoir & $\begin{array}{l}\text { Berfungsi, Reservoir ke } 2 \text { digunakan pada saat musim } \\
\text { kemarau saja }\end{array}$ & 2 \\
\hline & $\begin{array}{l}\text { Saringan Pasir } \\
\text { Lambat } \\
\text { Jaringan Transmisi }\end{array}$ & $\begin{array}{l}\text { Berfungsi, SPL digunakan hanya untuk penampungan ai } \\
\text { saja }\end{array}$ & 1 \\
\hline & $\begin{array}{l}\text { Jaringan Distribusi } \\
\text { Kran Umum }\end{array}$ & $\begin{array}{l}\text { Berfungsi } \\
\text { Berfungsi Sebagian }\end{array}$ & $\begin{array}{l}8.005,8 \mathrm{~m} \\
5\end{array}$ \\
\hline
\end{tabular}

Sumber : Data Olahan, 2017

Menurut petunjuk teknis Pamsimas (2015) pendekatan berbasis masyarakat menempatkan masyarakat sebagai pengambil keputusan utama dan penanggung jawab dalam seluruh tahapan mulai dari persiapan, perencanaan, pelaksanaan sampai dengan tahap pengoperasian dan pemeliharaan.

Semua tahapan dalam setiap proses kegiatan berpengaruh terhadap kinerja dan kesinambungan dari keberhasilan program Pamsimas, namun tahap perencanaan sangatlah penting, karena dengan adanya perencanaan dan pelaksanaan pembangunan yang baik dapat berpengaruh dalam keberlanjutan pemanfaatan bangunan yang telah dibuat atau tahap pasca konstruksi. Pada tahapan pasca konstruksi, pengoperasian dan pemeliharaan berada ditangan masyarakat pemanfaat, mengelola dan mengembangkan sarana air minum dan sanitasi yang telah terbangun secara mandiri, sehingga memberikan pelayanan yang berkelanjutan bagi masyarakat penerima manfaat.

Tabel 3. Hasil Wawancara pada Tahap Pengoperasian, Pemeliharaan, Pemantauan, dan Pengembangan di Jorong Gurun

\begin{tabular}{|c|c|c|}
\hline No & Uraian & Realisasi \\
\hline 1 & $\begin{array}{l}\text { DPMU/satker melakukan koordinasi dan penyebarluasan informasi mengenai kemajuan } \\
\text { program termasuk laporan keuangan dan lainnya }\end{array}$ & $\sqrt{ }$ \\
\hline 2 & $\begin{array}{l}\text { DPMU/satker memonitor dan mengevaluasi kebutuhan untuk meningkatkan kapasitas } \\
\text { pengelolaan program tingkat kabupaten }\end{array}$ & $\sqrt{ }$ \\
\hline 3 & $\begin{array}{l}\text { Penyusunan panduan operasi baku/ standar operasional pekerjaan (SOP) } \\
\text { pengoperasiaan program Pamsimas berupa pengoperasian sistem fisik dan } \\
\text { pembiayaan }\end{array}$ & $\sqrt{ }$ \\
\hline 4 & $\begin{array}{l}\text { Menetapkan sistem manajemen yang mengatur pengelolaan aset, institusi, termasuk } \\
\text { pembinaan terhadap institusi pengelolaan unit Pamsimas secara berkelanjutan }\end{array}$ & $\sqrt{ }$ \\
\hline 5 & $\begin{array}{l}\text { BP-SPAMS memberikan masukan terhadap rencana operasional dan pemeliharaan } \\
\text { untuk sarana terbangun, seperti rencana besaran iuran air dan proses pengelolaan } \\
\text { keuangan }\end{array}$ & $\sqrt{ }$ \\
\hline 6 & $\begin{array}{l}\text { BP-SPAMS memonitor pelaksanaan kegiatan konstruksi dan kegiatan lain dalam } \\
\text { RKM }\end{array}$ & $\sqrt{ }$ \\
\hline 7 & $\begin{array}{l}\text { BP-SPAMS menjalankan tugasnya sesuai dengan anggaran dasar dan anggaran } \\
\text { rumah tangga }\end{array}$ & $\sqrt{ }$ \\
\hline 8 & $\begin{array}{l}\text { BP-SPAMS merealisasikan kegiatan yang tertuang dalam RKM yang berkaitan dengan } \\
\text { tahap Pascakonstruksi dan PJM Pro-Aksi }\end{array}$ & $\sqrt{ }$ \\
\hline 9 & $\begin{array}{l}\text { Inspeksi air minum yaitu suatu kegiatan pengamatan dan penilaian terhadap sarana air } \\
\text { minum sistem perpipaan, sistem sumur dangkal, sistem sumur dalam }\end{array}$ & $\sqrt{ }$ \\
\hline 10 & $\begin{array}{l}\text { Inspeksi sanitasi pada sistem perpipaan untuk mengamati keberfungsian sarana mulai } \\
\text { dari penangkap air, intake, reservoir, pipa transmisi, pipa distribusi pada pengguna atau } \\
\text { pada titik pelayanan terakhir }\end{array}$ & $\sqrt{ }$ \\
\hline 11 & $\begin{array}{l}\text { Kegiatan operasional dan pemeliharaan adalah kegiatan yang dilakukan secara } \\
\text { rutin (harian, mingguan, bulanan dan tahunan) }\end{array}$ & $\sqrt{ }$ \\
\hline 12 & $\begin{array}{l}\text { BP-SPAMS mengoperasikan sistem pelayanan air minum, memonitor kuantitas dan } \\
\text { kualitas air yang dihasilkan, serta melakukan tindakan yang diperlukan apabila terjadi } \\
\text { kebocoran }\end{array}$ & $\sqrt{ }$ \\
\hline
\end{tabular}


13 Keberlanjutan teknis dari kegiatan Pamsimas yaitu berfungsinya secara benar dan dapat diandalkan terhadap teknologi serta pelayanan sistem air minum

14 Keberlanjutan teknis dari kegiatan Pamsimas yaitu kualitas air yang memenuhi standar kesehatan

15 Keberlanjutan teknis dari kegiatan Pamsimas yaitu dapat memberikan pelayanan dengan jumlah air yang memadai secara kontinu

16 BP-SPAMS Mengelola pelayanan pemakaian air minum sesuai kesepakatan masyarakat

17 BP-SPAMS mengorganisasi masyarakat untuk pelaksanaan pemeliharaan dan perbaikan jika dalam jumlah dan volume yang besar

18 Pemanfaat (masyarakat) diberikan pilihan untuk teknologi pelayanan sesuai dengan kemampuan pembiayaan (terjangkau), budaya dan tata cara keseharian

19 Masyarakat mengetahui kondisi dan perkembangan dalam penyelenggaraan program

20 Diberikan peluang kepada masyarakat untuk dapat menguasai aset yang ada, tidak saja pada hak pengelolaan, tetapi juga kepemilikan, agar penyelenggaraan Pamsimas dapat menjadi aset yang berkelanjutan dikembangkan oleh masyarakat

21 Kualitas dan kuantitas sistem penyediaan air minum merupakan tanggung jawab masyarakat bersama dengan badan pengelola yang telah ditunjuk

22 Pemeliharaan perlindungan daerah tangkapan air (P-DTA) untuk menjaga ketersediaan air baku

23 Daerah-daerah sumber air dilarang digunakan untuk pemanfaatan secara berlebihan dan mengeksplorasi di luar kepentingan konservasi sumber daya air

24 BP-SPAMS bersama masyarakat menetapkan tarif/iuran pemanfaatan sarana air minum dan sanitasi untuk pengoperasian dan pemeliharaan

25 Dana BP-SPAMS untuk membiayai operasi, pemeliharaan dan pengembangan

26 Dana tambahan untuk biaya operasional, biaya pemeliharaan dan perbaikan penyediaan air minum, honor petugas

27 Dana kegiatan operasional dan pemeliharaan terencana untuk menjaga agar sarana yang telah dibangun tetap dapat berfungsi dengan baik

28 Pengurus BP-SPAMS membuat pelaporan keuangan secara rutin dan pengadministrasian dokumen secara tertib setiap bulannya

29 Kader AMPL membantu pemerintah desa menyusun laporan tiga bulanan dan tahunan mengenai kinerja SPAMS dan BP-SPAMS kepada pemerintah kecamatan dan asosiasi pengelola SPAMS perdesaan

30 Pelaporan dan evaluasi pertanggungjawaban secara berkala kegiatan operasional dan pemeliharaan sarana air minum, serta biaya dan manfaatnya

31 Terbentuk kelompok masyarakat yang mampu mengelola dan mengembangkan prasarana air minum terbangun secara mandiri dan berkelanjutan

Sumber : Data Olahan, 2017

Keterangan: $\quad \sqrt{ }=$ dilakukan $\quad \mathrm{x}=$ tidak dilakukan

Pada tahun 2009, pembangunan sarana dan prasarana program Pamsimas berupa 1 intake yang sumber air bakunya berupa air permukaan, 1 bak penampung air (reservoir), 1 saringan pasir lambat, 5 kran umum, dan jaringan perpipaan transmisi dan distribusi ke rumah-rumah masyarakat $3.329,8 \mathrm{~m}$ '.

Pada tahun 2011, atas prestasinya dalam melakukan pengoperasian, pemeliharaan serta pengembangan jaringan distribusi air minum, Pemerintah memberikan bantuan penambahan dana untuk peningkatan yang ada di Jorong Gurun, sehingga dapat meningkatkan pengembangan penyediaan air minum berbasis masyarakat hingga ke Jorong lain, yaitu Jorong Lubuk Jantan. Untuk menambah debit air yang ada, masyarakat membangun kembali 1 intake, 1 reservoir dan saringan pasir lambat, serta penambahan jaringan perpipaan.

Debit sumber air baku yang kedua di Jorong Gurun sebesar 10 lt/dt, dengan jumlah penduduk jorong Gurun dan dusun Lubuk Jantan sebanyak 1563 jiwa. Jika ditotal jumlah debit air berdasarkan dua sumber tersebut sebanyak 13 lt/dt, maka debit tersebut mencukupi kebutuhan masyarakat yaitu sebanyak 1,085 lt/dt. Penyediaan sarana air minum membantu masyarakat Jorong Gurun dalam memudahkan aktivitasnya. Jika dahulu mereka harus mencari sumber air cukup jauh dari permukiman, kini masyarakat sudah dapat langsung 
menikmati air dirumahnya. Tetapi permasalahan yang sering terjadi, ketika musim kemarau, debit air tidak mencukupi kebutuhan masyarakat. Oleh sebab itu, anggota LKM, BPSPAMS bersama masyarakat mencari tambahan sumber air baku lagi untuk mencukupi kebutuhan masyarakat dikala musim kemarau.

Pada tahun 2015, masyarakat Jorong Gurun mengajukan proposal penambahan dana untuk kegiatan pengembangan sarana air minum yang telah ada. Pada tahun 2016, pemerintah kembali memberikan bantuan dana ke Jorong Gurun, melalui Program Pamsimas Hibah Insentif Kabupaten (HIK). Dana tersebut digunakan untuk penambahan pembangunan 1 intake yang sumber airnya berasal dari air permukaan, dan rehab sarana penyediaan air minum yang ada, serta pengembangan jaringan distribusi air minum ke masyarakat.

Debit sumber air baku yang ketiga di Jorong Gurun sebesar 3,5 1t/dt, dengan pertambahan jumlah penduduk jorong Gurun dan dusun Lubuk Jantan pada tahun 2016 sebanyak 2033 jiwa. Jika ditotal jumlah debit air berdasarkan dua sumber yang digunakan saat ini adalah 6,5 lt/dt, maka debit tersebut mencukupi kebutuhan masyarakat yaitu sebanyak $1,41 \mathrm{lt} / \mathrm{dt}$.

Di Jorong Gurun, terdapat 3 stop kran pembagi untuk mengatur distribusi air ke masyarakat, serta ada 6 stop kran penguras pipa, yang digunakan untuk membersihkan pipa (mengeluarkan kotoran yang ada di dalam pipa). Dengan adanya stop kran pembagi tersebut, ketika musim kemarau, BP-SPAMS mengatur waktu pemakaian air ke rumahrumah masyarakat. Sehingga distribusi air lancar.

Kegiatan operasioanal dan pemeliharaan yang ada di Jorong Gurun dilakukan rutin setiap harinya. Untuk pembersihan intake, reservoir dilakukan setiap bulannya, atau minimal tiga bulan sekali. Setiap ada kendala terhadap sarana penyediaan air minum, BPSPAMS bertanggung jawab penuh dalam penyelesaiaannya.

Di Jorong Gurun mayoritas penduduknya bekerja sebagai petani, yaitu petani gambir. Harga gambir yang saat ini menjanjikan dipasaran, membuat masyarakat berlomba untuk membuka lahan baru di daerah sekitar sumber air. Masyarakat belum memikirkan kondisi perlindungan terhadap daerah tangkapan air, hal ini tentu dapat mengurangi debit air yang ada nantinya.

Tarif iuran air minum per-M3 ditetapkan berdasarkan keputusan bersama yaitu sebesar Rp. 500 / M3 jika pemakaian dibawah 20 M3, sedangkan pemakaian diatas 20 M3 dikenakan tarif Rp. 1000 / M3. Uang hasil dari iuran air minum, di kelola oleh BP-SPAMS yang sebagian digunakan untuk operasional bulanan, juga pemasukan untuk Nagari, serta dapat membantu kegiatan lain yang ada di Jorong Gurun, selain itu Jorong Gurun juga mempunyai kas untuk antisipasi kerusakan yang akan terjadi di masa yang akan datang. Akan tetapi, iuran masyarakat ini masih sangat kecil, sehingga uang yang terkumpul sedikit. Hendaknya perlu dimusyawarahkan lagi mengenai tarif iuran ini agar kas yang terkumpul dapat menanggulangi kerusakan dan perkembangan ke depan, tanpa perlu mengajukan pendanaan ke Pemerintah.

BP-SPAMS Jorong Gurun membuat laporan pembukuan dan laporan pertanggungjawaban per tiga bulan. Laporan tersebut diketahui oleh pihak Nagari dan Konsultan program Pamsimas. Di Jorong Gurun, telah ditetapkan aturan- aturan penggunaan sarana air minum, jika terjadi pelanggaran, maka masyarakat yang melanggar akan dikenakan sanksi. Hingga saat ini, hampir seluruh penduduk di Jorong Gurun telah menggunakan air minum dari program Pamsimas.

\section{SIMPULAN}

Pengelolaan Program Pamsimas di Jorong Gurun ini terlaksana dengan baik. Pengelolaan mengacu pada 5 aspek keberlanjutan program Pamsimas, dari penelitian ini dapat ditarik kesimpulan: 
1. Adanya keberlanjutan teknis. Sarana dan prasarana berfungsi secara benar dan dapat diandalkan terhadap teknologi serta pelayanan sistem air minum dan dapat memberikan pelayanan dengan jumlah air yang memadai secara kontinu dengan kualitas air yang memenuhi standar kesehatan.

2. Keberlanjutan pendanaan, pendanaan dari iuran masyarakat sangat sedikit, sehingga belum mencukupi untuk melakukan pengembangan sarana dan prasana secara mandiri.

3. Adanya Keberlanjutan kelembagaan yang tersistem, BP-SPAM dan LKM dapat melakukan kewajiban dan bertanggung jawab terhadap tugasnya.

4. Adanya Keberlanjutan sosial, ditandai dengan semakin mudahnya masyarakat dalam pemenuhan akan air minum.

5. Kurangnya keberlanjutan lingkungan, sumber air akan menghadapi banyak ancaman, karena perubahan tata guna lahan di sekitar sumber air.

\section{DAFTAR PUSTAKA}

Afriadi, Taufik dan Wahyono, Hadi, 2012. Partisipasi Masyarakat dalam Penyedian Air Minum dan Sanitasi Berbasis Masyarakat (PAMSIMAS) di Kecamatan Simpur Kabupaten Hulu Sungai Selatan, Jurnal Pembangunan Wilayah \& Kota, Planologi Universitas Diponegoro, Volume 8 (4) : 341-348.

Pamsimas, Fieldbook proses identifikasi masalah dan analisis situasi, PAMSIMAS, 2010.

Insani, Safira, 2016. Efektivitas Program Penyediaan Air Minum dan Sanitasi Berbasis Masyarakat (PAMSIMAS) di Temanggung, Skripsi Jurusan Ilmu Administrasi Negara, Fakultas Ilmu Sosial, Universitas Negeri Yogyakarta.

Kholiq, Abdul, 2014. Evaluasi Keberhasilan Program Air Minum dan Sanitasi (PAMSIMAS) di Kabupaten Tegal dan Kabupaten Brebes, Thesis Magister Teknik Sipil, Program Studi Teknik Sipil, Fakultas Teknik, Universitas Majalengka, Jawa Barat

Nahor, Josmar Lambok Banjar, 2010. Faktor-Faktor yang mempengaruhi Kegagalan dan Keberhasilan Pengelolaan Sistem Penyediaan Air Minum di Desa Wuran dan Tarinsing Kabupaten Barito Timur, Thesis Magister Teknik Pembangunan Wilayah dan Kota, Universitas Diponegoro 